Preventive Care in Nursing and Midwifery Journal

2020; $10(2): 42-47$

\title{
The Effectiveness of Orange Essential Oil Aromatherapy on Blood Pressure, Pulse Rate, and Respiratory Rate of Patients Scheduled for Coronary Angiography: A Clinical Trial
}

\author{
${\text { Tahmasebi }{ }^{1 *}}^{*}$, Abasi $E^{2}$ (i), Pourhosein $\mathrm{S}^{3}$ (B) \\ ${ }^{* 1}$ Instructor, Department of Nursing, School of Nursing and Midwifery, Islamic Azad University, Sari Branch, Sari, Iran \\ ${ }^{2} \mathrm{MSc}, \mathrm{PhD}$ Candidate in Reproductive Health, School of Nursing and Midwifery, Islamic Azad University, Sari Branch, Sari, Iran \\ ${ }^{3} \mathrm{MSc}$, Department of Nursing, School of Nursing and Midwifery, Islamic Azad University, Sari Branch, Sari, Iran \\ *Corresponding Author: Islamic Azad University Sari Branch, Nursing and Midwifery Faculty, Sari, Iran
}

Tel: 0098- 9112514100

Email: htahmasebi@iausari.ac.ir

Received: 19 Oct $2020 \quad$ Accepted: 21 Nov 2020

\begin{abstract}
Background: Patients scheduled for angiography experience pre-operative anxiety, which affects vital signs. Objectives: The current study aimed to investigate the effectiveness of orange essential oil aromatherapy on blood pressure, pulse rate, and respiratory rate of patients before coronary angiography.

Methods: In this clinical trial, 70 patients scheduled for coronary angiography were separated into two groups of intervention and control. For those in the intervention group, two drops of orange essential oil were drip by emitters on a polyethylene handkerchief attached to the collar of the participants. Then, they were asked to breathe normally for 20 minutes. Vital signs were recorded before and after providing the intervention. Data were analyzed using SPSS version 16 using Chi-square, Fisher's exact test, independent ttest, U Mann-Whitney, Paired Wilcoxon, and paired t-test.

Results: There was no significant difference between the two groups concerning the mean vital signs before providing the intervention. However, after providing the intervention, a significant difference was found concerning pulse rate $(71.3 \pm 26.79)$, respiratory rate $(15.2 \pm 11.04)$, and systolic blood pressure $(117.9 \pm 31.47)$ between the two groups $(\mathrm{P}<0.001)$. In the control group, no significant difference was found concerning the pulse rate (75.3 \pm 06.72$)$, respiratory rate (17.2 \pm 18.28$)$, and systolic blood pressure (123.8 \pm 91.91$)$ before and after providing the intervention $(\mathrm{P}>0.001)$, and this difference was significant between the two groups $(\mathrm{P}<0.001)$. Also, there was no significant difference between the two groups concerning the diastolic blood pressure $(\mathrm{P}>0.001)$.

Conclusion: This study demonstrated that orange essential oil, as a complementary method, can reduce pulse rate, respiratory rate, and systolic blood pressure in people undergoing coronary angiography. Therefore, it can be considered as a safe and cheap alternative therapeutic option.
\end{abstract}

\section{Keywords: orange essential oil; pulse rate; respiratory rate; coronary angiography}

\section{Introduction}

Coronary angiography is a definitive, reliable, and invasive method to diagnose coronary artery diseases [1]. It's the most widely used diagnostic modality for cardiac patients [2]. In 2010, over 3 million angiographies are performed in the United States [3]. In Iran, more than 260,000 cases of coronary angiography are performed annually [4]. Although it has several advantages, it also contains disadvantages such as high anxiety, mainly due to its invasive nature, which in turn affects the vital signs, such as increased pulse rate, respiratory rate, and systolic and diastolic blood pressure [5]. Vital signs are objective criteria for assessing essential physiological functions of the body, which are also useful for assessing the need for angiography [6]. Increased vital signs is common before angiography that worsens the patient's health condition and thereby affects the angiography outcomes [7]. Anxiety stimulates the sympathetic nervous system causing an increase in heart rate, heart 
excitability, and blood pressure, which in turn increases the heart's need for oxygen and disrupts blood supply to heart cells [2]. Anxiety and vital signs are mutually supportive [6]. There are pharmaceutical and non-pharmaceutical strategies to control anxiety [8]. Since pharmaceutical strategies may cause side effects, the tendency towards non-pharmaceutical strategies is increasing (e.g. complementary medicine) [9]. Aromatherapy is a common method in complementary medicine [10], that, if needed, can be used by nurses.

Complementary medicine is a low-risk, costeffective treatment with limited side effects, which its application is increasing [11,12]. Orange essential oil, also known as Citrus aurantium, is widely used for aromatherapy [13]. It stimulates the central nervous system and has sedative, antiinflammatory, antispasmodic, and anti-bloating effects. Besides, it can reduce blood pressure and dilation [14]. Also, some studies mentioned the anxiolytic effects of orange essential oil during labor [15] and for dentistry services [16]. Findings about the effects of orange essential oil on vital signs are controversial $[17,18]$ and further studies are needed. Furthermore, based on the field observations of the researcher, in most cases, the respiratory rate and heart rate of patients increases before angiography, which in some cases results in delaying or canceling angiography. On the other hand, monitoring and controlling vital signs are among important nursing care. The current study aimed to investigate the efficacy of orange essential oil aromatherapy on blood pressure, pulse rate, and respiratory rate of patients before coronary angiography in Fatemeh Zahra Hospital in the city of Sari in 2019.

\section{Methods}

The current clinical trial is confirmed by the Ethics Committee of the Islamic Azad University Sari Branch (code:11-1397 R.IAU.SARI.REC). In the present study, 70 patients scheduled for coronary angiography admitted to the angiography ward of Fatemeh Zahra Hospital in the city of Sari, which is the referral center of Mazandaran province, in 2018 are investigated.

Inclusion criteria were complete consciousness, coronary angiography for the first time, not receiving invasive procedures before angiography, and not using sedatives or other therapeutic interventions (e.g. herbal essential oils and medications) six weeks before angiography. Exclusion criteria were sudden changes in vital signs, dangerous cardiac dysrhythmias, and unwillingness to continue the study. The sample size was calculated using the following formula [19]:

$$
n=\frac{\left(Z_{1-\alpha / 2}+Z_{1-\beta}\right)^{2}\left(S_{1}^{2}+S_{2}^{2}\right)}{\left(\mu_{1}-\mu_{2}\right)^{2}}
$$

Type one error and type two error were considered as $5 \%$ and $2 \%$, respectively. The study power was also considered to be $80 \%$. Participants were randomly divided into two groups of 35 subjects: control and intervention. Two subjects of the control group were excluded because they couldn't fill the questionnaire due to chest pain and receiving sedatives. Data were collected using a questionnaire on demographic (i.e. age, gender, married status, history of diseases, and type of health insurance) and disease information, vital sign sheet, and medical equipment such as barometer. Information were recorded before and immediately after the angiography. The validity of the mercury barometer was assessed by calibrating the device and its reliability was assessed using the testretest method. For this purpose, the blood pressure of 10 randomly selected patients was measured two times with a distance of five minutes. Then, their mean correlation was compared to the correlation coefficient of the lower $95 \%$ of the instrument. Blood pressure was measure after a short rest in laying down position. Also, pulse and respiratory rates were manually recorded for one minute.

The orange essential oil was obtained from the Gorgan Essence Company. For those in the intervention group, one hour before the angiography, two drops of orange essential oil were drip by emitters on a polyethylene handkerchief attached to the collar of the participants. Then, they were asked to breathe normally for 20 minutes [20]. Subjects of the control group received two drops of distilled water (placebo), with similar color as the orange essential oil. The vital signs were measured before and after the intervention. It worth noting that a cardiologist supervised the study.

Data were analyzed using SPSS version 16 by chi-square, Fisher's exact test, independent t-test, 
U Mann-Whitney, paired Wilcoxon, and t-tests. Statistical significance was considered when pvalue $<0.05$. The chi-square and Fisher's exact tests were used to compare qualitative variables. As data were not normally distributed, U MannWhitney and paired Wilcoxon tests were used for intra- and inter-comparison of groups before and after the intervention, respectively.

\section{Results}

In total 70 subjects participated in the present study, but in the control group, two subjects were removed due to incompleteness of questionnaires, because of chest pain and receiving sedatives. Therefore, data of 35 subjects in the orange essential oil and 33 subjects in the control group were analyzed. The mean age of participants was $58.8 \pm 6.4$ and most of them were female $(56.4 \%)$ and married (77.2\%). Most of the participants were educated up to primary only $(46.5 \%)$ and $89.1 \%$ of them had background diseases. There was no significant difference between the two groups concerning demographic information (Table 1).

Table 1: Demographic information of participants separated by the group

\begin{tabular}{|c|c|c|c|c|}
\hline \multicolumn{2}{|c|}{ Property } & $\begin{array}{c}\text { Orange essential oil } \\
35=n\end{array}$ & $\begin{array}{c}\text { Control } \\
\text { 33=n }\end{array}$ & $\mathbf{P}$ \\
\hline \multirow{2}{*}{ Gender* } & Male & $(4.51) 18$ & $(4.42) 14$ & 457.0 \\
\hline & female & $(6.48) 17$ & $(6.57) 19$ & \\
\hline \multirow{3}{*}{$\begin{array}{l}\text { Marriage } \\
\text { status }\end{array}$} & Married & $(9.2) 1$ & $(1.6) 2$ & 405.0 \\
\hline & Single & $(6.88) 31$ & $(8.75) 25$ & \\
\hline & other & $(6.8) 3$ & $(2.18) 6$ & \\
\hline \multirow{4}{*}{$\begin{array}{l}\text { Education } \\
\text { level }^{* *}\end{array}$} & Illiterate & $(0.40) 14$ & $(5.51) 17$ & 244.0 \\
\hline & Primary & $(6.28) 10$ & $(2.21) 7$ & \\
\hline & Tertiary & $(6.28) 10$ & $(2.15) 5$ & \\
\hline & University & $(9.2) 1$ & $(1.12) 4$ & \\
\hline \multirow{2}{*}{$\begin{array}{l}\text { Background } \\
\text { disease }^{* * *}\end{array}$} & Yes & $(6.8) 3$ & $(1.9) 3$ & 00.1 \\
\hline & No & $(4.91) 32$ & $(9.90) 30$ & \\
\hline \multicolumn{2}{|c|}{ Age (Year) ${ }^{* * * *}$} & $21.6 \pm 80.57$ & $11.6 \pm 64.58$ & 498.0 \\
\hline
\end{tabular}

U Mann-Whitney $^{* * *}$; Fisher's exact test ${ }^{* *}$; Chi-square ${ }^{*}$.

Vital signs (pulse rate, respiratory rate, and systolic and diastolic blood pressure) were measured on the day that the patient was scheduled for angiography (before any intervention). Based on the results there was no significant difference between the two groups before providing the intervention; however, after providing the intervention, the two groups were significantly different concerning pulse rate, respiratory rate, and systolic blood pressure (Table 2). 
Table 2: Comparison of blood pressure, pulse rate, and respiratory rate in control and intervention groups before and after the intervention

\begin{tabular}{ccccc}
\hline Variable & Time & $\begin{array}{c}\text { Control } \\
\pm \text { SDMean }\end{array}$ & $\begin{array}{c}\text { Orange essential oil } \\
\mathbf{\pm S D} \text { Mean }\end{array}$ & $\mathbf{P}^{* *}$ \\
\hline \multirow{3}{*}{ Pulse rate } & Before & $85.5 \pm 0.74$ & $64.3 \pm 20.74$ & 633.0 \\
\cline { 2 - 5 } & After & $73.3 \pm 06.75$ & $79.3 \pm 26 / 71$ & 001.0 \\
\cline { 2 - 5 } Respiratory rate & P* & 368.0 & 000.0 & \\
\cline { 2 - 5 } & Before & $27.2 \pm 33.17$ & $41.2 \pm 63.17$ & 444.0 \\
\cline { 2 - 5 } & After & $28 / 2 \pm 18 / 17$ & $04.2 \pm 11.15$ & 000.0 \\
\hline \multirow{2}{*}{$\begin{array}{c}\text { Systolic blood } \\
\text { pressure }\end{array}$} & Pefore & $50.10 \pm 48.123$ & $80.12 \pm 09.123$ & 560.0 \\
\cline { 2 - 5 } & After & $91.8 \pm 91.123$ & $47.9 \pm 31.117$ & 001.0 \\
\cline { 2 - 5 } $\begin{array}{c}\text { Diastolic blood } \\
\text { pressure }\end{array}$ & Pefore & $50.6 \pm 12.77$ & $34.8 \pm 71.77$ & 949.0 \\
\cline { 2 - 5 } & After & $59.7 \pm 01.77$ & $89.7 \pm 86.77$ & 939.0 \\
\cline { 2 - 5 } & P* & 713.0 & 862.0 & \\
\hline
\end{tabular}

* Intra-group comparison using the paired Wilcoxon test

** Comparing groups using Mann-Whitney $\mathbf{U}$ test

\section{Discussion}

This study demonstrated that inhaling orange essential oil could significantly reduce systolic blood pressure, pulse rate, and respiratory rate in the intervention group compared to the control group. Mi-Ra et al. (2018), in a study entitled "Effectiveness of aromatherapy on vital signs, physical, and physical Stress relief and sleep quality of students", concluded that aromatherapy had a positive physiological effect on vital signs, physical, and physiological stress relief, and sleep quality of students [21]. Also, Jafari et al. (2013), in a study entitled "effect of aromatherapy with orange essential oil on salivary cortisol and pulse rate in children during dental treatment", reported a significant association between decreasing anxiety and heart rate [16]. In another study, Moradi et al. (2015), in a study entitled "effects of Lavender aromatherapy on the anxiety and vital signs of patients with ischemic heart diseases hospitalized in cardiac intensive care units" showed that this intervention could reduce anxiety level in patients with ischemic heart disease and had a positive effect on vital signs [22]. Yadegari et al. (2015) in a study aimed to investigate the effect of inhaling jasmine flower on some physiological parameters in patients before laparotomy in the general surgery ward, reported a significant difference between the two groups concerning physiological variables such as pulse rate, respiratory rate, and systolic and diastolic blood pressure [11]. These studies demonstrated the positive effect of aromatherapy on reducing anxiety and improving vital signs of patients before providing medical interventions. In contrast, CevIlk (2017) reported that inhaling orange and lavender essential oil didn't affect the anxiety and vital signs of nursing students while giving an injection for the first time [17]. Also, Hekmat Poe et al. (2017) investigated the effect of orange essential oil on pain and vital signs of patients with limb fractures and concluded that although the blood pressure was lower in the intervention group, it was not statistically significant compared to the control group [18]. As mentioned before, findings concerning the effect of aromatherapy with orange essential oil are controversial. This difference can be attributed to various reasons such as using different oils, duration of the study, and the administration method. Therefore, the authors suggest performing further studies on special patients and different groups.

\section{Conclusion}

This study demonstrated that aromatherapy can be used as a complementary method along with routine treatments or even as an alternative method. Therefore, aromatherapy can be used as an effective and uncomplicated strategy for reducing anxiety in anxious situations. Hence, nurses can use this method for stabilizing vital signs. 


\section{Acknowledgements}

This manuscript is derived from a research project (code 6914-5). The authors would like to thank administrators of the Islamic Azad University Sari Branch and Fateme Zahra Hospital for their help in conducting this study.

\section{Conflict of interest}

The authors declare no conflict of interest.

\section{References}

1. O'Connell Smeltzer SC, Bare BG, Hinkle JL, Cheever KH. Brunner \& Suddarth's Textbook of Medical-surgical Nursing. $12^{\text {th }}$ ed. Philadelphia, PA: Lippincott Williams \&Wilkins; 2017.

2. Pourmirzaie M, Teymouri F, Farsi Z, Rajai N. A Review of the effect of aromatherapy on Anxiety and Hemodynamic Parameters in patients undergoing coronary angiography. Journal of the School of Army Nursing. 2018; 17(2): 33. [In Persian]

3. Okkesim Ş, Kara S, Kaya MG, Asyali MH. Analysis of coronary angiography related psychophysiological responses. Biomed Engin Onlin. 2011; 10(1): 1-19.

4. Molavi Vardanjani M, Masoudi Alavi N, Sadat Razavi N, Aghajani M, Azizi-Fini E, Morteza Vaghefi S. A randomizedcontrolled trial examining the effects of reflexology on anxiety of patients undergoing coronary angiography. Nurs Midwifery Stud. 2013; 2(1): 33.

5. Delewi R, Vlastra W, Rohling WJ, et al. Anxiety levels of patients undergoing coronary procedures in the catheterization laboratory. Int $\mathbf{J}$ cardiol. 2017; 228: 926-30.

6. Mohammad-Aliha J, Najafi-Ghezeljeh T, Aghahoseini F, Rahmani R. Effect of combined inhalation of Lavender oil, Chamomile and Neroli oil on vital signs of people with acute coronary syndrome. J Cardiovasc Nurs. 2016; 5(3):42-52. [In Persian]

7. Mei L, Miao X, Chen H, Huang X, Zheng G. Effectiveness of Chinese Hand Massage on Anxiety Among Patients Awaiting Coronary Angiography: A Randomized Controlled Trial. J Cardiovasc Nurs. 2017; 32(2): 196-203.

8. Nategh M, Heidari MR, Ebadi A, Kazemnejad A, Babaei Beigi MA. Effect of Lavender aromatherapy on hemodynamic indices among patients with acute coronary syndrom:a randomized clinical trial, Iran j Crit Care Nurs. 2015; 7 (4): 208-201.

9. Aali E, Mahmoudi R, Kazeminia M, Hazrati R, Azarpey F. Essential oils as natural medicinal substances: review article. Tehran Univ Med J (TUMJ). 2017; 75(7): 480-89. [In Persian]

10. Tahmasebi H, Zafari M , Darvishhkezri H , Abasi E. The effect of aroma inhalation on systolic blood pressure, pulse rate and the number of breathing before coronary angiography. Nurs Midwifery J. 2015; 12(11): 1012-17.

11. yadegary M, Mahmoodi Shan GR, Vakili MA, Fazel A, Kamkar MZ. Effect Of Essential Oil Jasmine Inhalation On Physiological Index Of Laparotomy Patients In General Surgery Department. Jorjani Biomed. 2018; 5(1): 32-41. [In Persian]

12. Nematollahi MR, Bazeli J, Basiri Moghaddam M, Aalami H. Effect of aromatherapy on anxiety in patients with acute coronary syndrome hospitalized in cardiac care unit. Bali Med J. 2017; 6(2): 331-336.

13. Jafarzadeh M, Arman S, Farahbakhsh Pour F. Effect of aromatherapy with orange essential oil on salivary cortisol and pulse rate in children during dental treatment: A randomized controlled clinical trial. Adv Biomed Res. 2013; 2: 10.

14. Aligani Renani H, Noruzi Zamengani M, Asnafi A, Latifi M .The effect of aromatherapy with orange essential oils on sleep quality in the school-age children whit ALL. Complementary Med J. 2015; 5(1): 1112-22. [In Persian]

15. Rashidi-Fakari F, Tabatabaeichehr M, Mortazavi H. The effect of aromatherapy by essential oil of orange on anxiety during labor: A randomized clinical trial. Iran J Nurs Midwifery Res . 2015; 20(6): 661-64.

16. Jafarzadeh M, Arman S, Farahbakhsh Pour F. Effect of aromatherapy with orange essential oil on salivary cortisol and pulse rate in children during dental treatment: A randomized controlled clinical trial. Adv Biomed Res. 2013; 2: 1-7.

17- Çevik C, İnce S, Ayçeman N, Ergin E. Effects of Aroma Inhalation on Anxiety and Vital Signs of Nursing Students during Their First Blood Drawing Practice. Int J Health Sci \& Res. 2017; 7(2): 243-52.

18- Hekmatpou D, Pourandish Y, Farahani PV, Parvizrad R. The effect of aromatherapy with the essential oil of orange on pain and vital signs of patients with fractured limbs admitted to the 
emergency ward: A randomized clinical trial. Indian J Palliat Care. 2017; 23(4): 431-36.

19. Day S, Graham D. Sample size estimation for comparing two or more treatment groups in clinical trials. Stat Med .1991; 10(1): 33-43.

20-Tahmasebi H, Poorkhiz A,Abdi Joubari. Comparing the Aromatherapeutic Effects of Orange and Lavender Essential Oils on Anxiety and Physiological Indicators in Patients Undergoing Coronary Angiography: A Clinical Trial Study. Med Surg Nurs J. 2019: 8(3): e98459.
21- Mi-Ra j, Ju-Duck k, Dae-Jin B. Effectiveness of aromatherapy to vital sign, psychological and physical stress relief and sleep quality in PreHypertension. Indian J Public Health Res \& Dev. 2018; 9(9): 1252-58.

22- Moradi Kh, Ashtarian H, Darabi F, Hashemian H, Saifi F. A survey on the effects of Lavender aromatherapy on the anxiety and vital signs of patients with ischemic heart diseases hospitalized in cardiac intensive care units. J Clin Res Paramed Sci. 2016; 4(4): 301-10. [In Persian] 